\title{
A Rare Finding of Pulmonary Trauma: Pseudocyst
}

\author{
Pulmoner Travmanın Nadir Bir Bulgusu: Psödokist
}

\author{
İsa Döngel ${ }^{1}$, Hasan Ekrem Camaş ${ }^{1}$, Ali Dur ${ }^{2}$ \\ 'Department of Thoracic Surgery, Faculty of Medicine, Süleyman Demirel University, Isparta, Turkey \\ ²Department of Emergency, Bezmialem Vakıf University Medical Faculty Hospital, İstanbul, Turkey
}

\begin{abstract}
Pulmonary parenchymal injury occurring after blunt thoracic trauma varies from simple contusion to laceration. Posttraumatic pulmonary pseudocyst is a rare complication of blunt thoracic trauma. It is a benign lesion which does not have its own epithelial component, and is mostly seen in children and young adults. Resorption undergoes an average of three months, but it could be transformed rarely into an abscess or cyst formation. Computed tomography is important in diagnosing pseudocysts. The majority of traumatic pulmonary pseudocysts are benign self-limiting lesions which do not require specific treatment. Indications for surgery are limited and can only be applied when complications develop. We aimed to report a case of pulmonary pseudocyst, which is a rare finding of blunt chest trauma due to a fall from a height, in the light of the literature.
\end{abstract}

Keywords: Blunt chest trauma, pseudocysts, pulmonary contusion

Received: 23.09.2012 Accepted: 11.11.2012

Available Online Date: 19.12.2013

\section{ÖZET}

Künt toraks travması sonrası meydana gelen akciğer parankim yaralanmaları basit kontüzyondan, laserasyonlara kadar değişir. Post-travmatik akciğer psödokisti künt toraks travmalarının nadir görülen bir komplikasyonu olup, kendine ait epiteli olmayan benign karekterli lezyonlardır. Çoğunlukla çocuklar ve genç erişkinlerde görülür. Ortalama üç ay içerisinde rezolüsyona uğrar, fakat nadirde olsa abse formasyonuna veya progresif olarak büyüyerek tansiyon kistine dönüşebilir. Bilgisayarlı tomografi psödokistlerin görüntülenmesinde önemlidir. Travmatik pulmoner psödokistlerin büyük bir kısmı spesifik bir tedaviye gerek göstermeksizin kendini sınılayan iyi huylu lezyonlardır. Cerrahi tedavi endikasyonu nadir olup yalnızca komplikasyonlar geliştiğinde uygulanabilir. Biz burada yüksekten düşmeye bağlı, künt toraks travmasının nadir bir bulgusu olan psödokist olgusunu literatür bilgileri ışığında sunmayı amaçladık.

Anahtar Kelimeler: Künt toraks travması, psödokist, akciğer kontüzyonu

Geliş Tarihi: 23.09.2012 Kabul Tarihi: 11.11.2012

Çevrimiçi Yayın Tarihi: 19.12.2013

\section{Giriş}

Künt toraks travması sonrası meydana gelen akciğer parankim yaralanmaları basit kontüzyondan ciddi parankim laserasyonlarına kadar değişebilen bir spektrum içerisinde olabilir. Post-travmatik akciğer psödokisti künt toraks travmalarının nadir görülen bir komplikasyonu olup, genellikle çocuk ve genç erişkinlerde görülen iyi huylu lezyonlardır. Büyük bir kısmı herhangi bir spesifik tedaviye gerek kalmaksızın sekel bırakmadan iyileşirler (1). Psödokistlerin oluşumunda iki mekanizma öne sürülmekte; birincisi akciğerin bir bölgesinin ani kompresyonu ve sıkışması ile periferik bronşiyal ağacın bir segmentinin kapanarak bu alan içerisinde oluşan basınca bağlı alveolar duvarların rüptürü, ikinciside akciğer parankimini yırtan ve hasarlayan kontüzyon dalgalarının bir sonucu meydana geldiği yönündedir $(1,2)$. Bu olgu sunumunda hasta onamı alınarak yüksekten düşmeye bağlı, künt toraks travmasının nadir bir bulgusu olan psödokist oluşum mekanizmalarını ve tedavi yaklaşımlarını literatür bilgileri ışığında sunmayı amaçladık.

\section{Olgu Sunumu}

Otuz iki yaşında erkek hasta, yaklaşık 9 metre yükseklikten düşme nedeni ile hastanemiz acil servisinde değerlendirildi. Hastada multipl kot fraktürü, pnömotoraks, akciğer kontüzyonu, kontüzyon içerisinde psödokist oluşumu, pelvis iliak kanat ve vertabra 

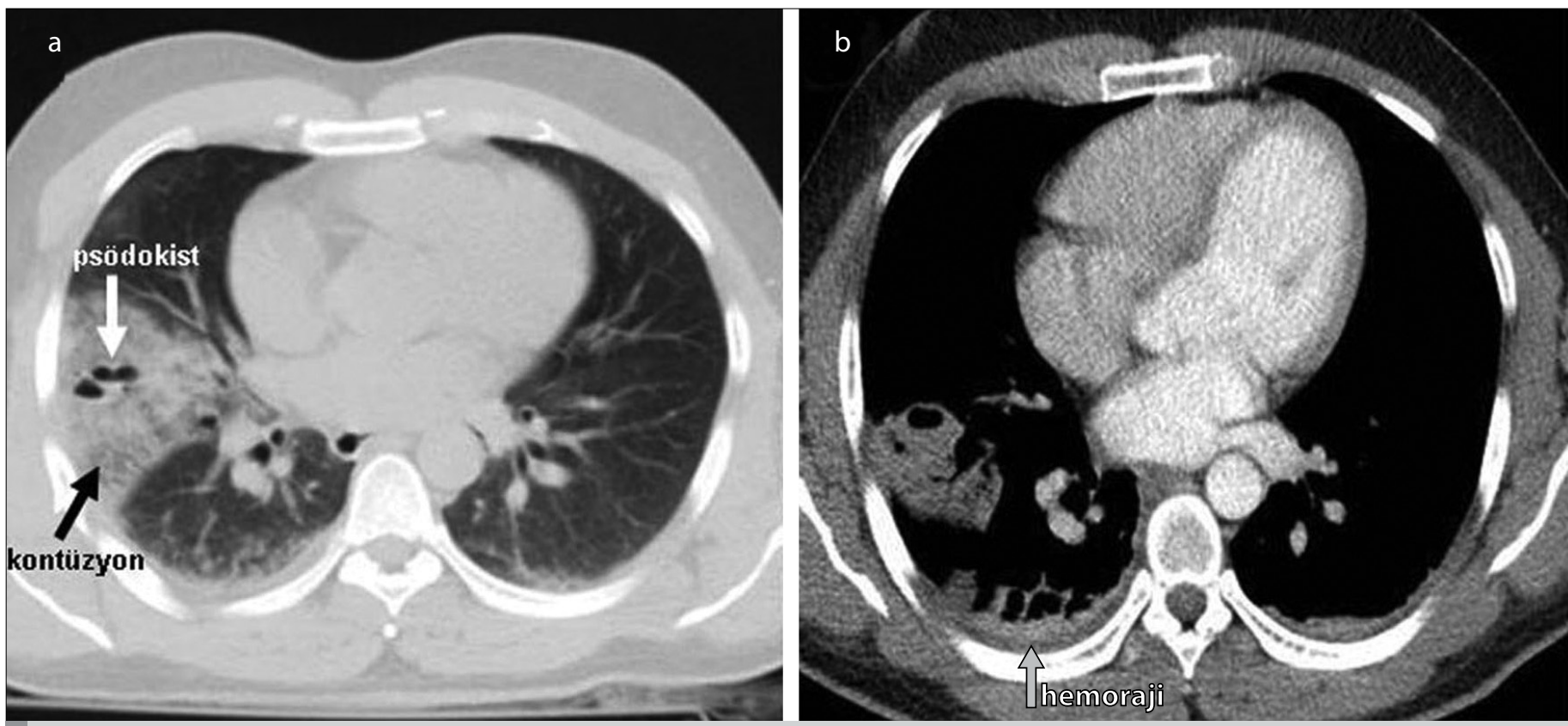

Resim 1. a. Pulmoner kontüzyon (siyah ok) ve santralde psödokist görünümü (beyaz ok) gözlenmekte. b. Travma sonrası aksiyal bilgisayarlı tomografi'de parankimal ve kemik pencerede sağ hemitoraksda alt lob laterobazalde hemorojiye ait dansite artışı (gri ok)

transvers proçes fraktürleri saptandı. Hastanın acil servis muayenesinde; kan basıncı: $120 / 70 \mathrm{mmHg}$, nabız: 88 , ateş: $37.6^{\circ} \mathrm{C}$, solunum sayısı 20, oda havasında SpO2: \%92, sağ hemitoraksda ağrı, hassasiyet, ciltte ekimoz, dinlemekle solunum sesleri sola göre azalma ve ince raller mevcuttu. Laboratuvar ve kan gazı değerleri normal sınılarda idi. Illgili travmatolojik konsültasyonları tamamlandıktan sonra kliniğimize yatırıldı. Hastaya geniş spektrumlu antibiyotik, analjezik antiinflamatuar, mukolitik ekspektoran ve bronkodilatör tedavi başlandı. Solunum eksersizi uygulandı, soğuk buhar ve aralıklı (2 L/dak.) oksijen tedavisi verildi. Hastanın direk grafilerinde sağ multipl kot fraktürü ve sağ beş ve yedinci kosta lateral duvarına lokalize non homojen dansite artışı gözlendi. Bilgisayarlı tomografi'de parankimal ve kemik pencerede sağ hemitoraks alt lob laterobazal segmentte hemorojiye ait dansite artışı ve santralde psödokist görünümü şeklinde rapor edildi (Resim 1a, b). Hastada gelişen pnömotoraks nedeni ile tüp torakostomi uygulandı ve akciğer ekspansiyonu sağlandıktan sonra dreni çekildi. Bir haftalık takibimiz sonucunda klinik ve radyolojik olarak stabil olan hasta yatışının yedinci günü taburcu edildi. Hastanın poliklinik takiplerinde iki ay sonra çektirilen kontrol tomografisinde sağ akciğer kontüzyonu ve kontüzyona bağlı psödokist oluşumunun kaybolduğu, sadece parankim kesitlerinde minimal bir fibrotik sekel görünümü izlenmekte idi (Resim 2a, b).

\section{Tartışma}

Pulmoner post-travmatik psödokist klinik olarak, intrapulmoner hemotom veya kontüzyondan daha az rastlanan nadir bir durumdur. Genellikle 30 yaş altında çocuklar ve genç erişkinlerde görülür. Çoğunlukla künt toraks travmasına bağlı oluşur. Bu yaşlarda sık görülmesinin sebebi künt toraks travmalarında toraks duvarının elastikiyetine bağlı sıkışması, visseral plevranın salim olması ve bunun sonucunda pulmoner parankimin kolayca yaralanabilmesinden kaynaklanmaktadır (3).
Hastamızda künt toraks travmasına bağlı sağ multipl kot fraktürü, pnömotoraks, akciğer kontüzyonu ve kontüzyon içerisinde psödokist oluşumları mevcuttu. Hasta ilgili kliniklerle değerlendirildikten sonra kliniğimize yatııılı. Pulmoner kontüzyon ve psödokist varlığında en sık karşılaşılan semptomlar; öksürük, göğüs ağrısı ve hemoptizi olmakla birlikte bazı durumlarda erken dönemde ateş yükseklikleri olabilir. Hastamızda erken dönemde öksürük, göğüs ağrısı ve hemoptizi bulguları mevcuttu, otuz sekizin üzerine çıkan ateş gözlenmedi. Bu semtomlar daha çok psödokiste bağlı olmayıp pulmoner kontüzyona bağlıdır. Bu hastalarda ağrı kontrolü ve ek komplikasyonlarla mücadelenin erken dönemde önem arz ettiği kanaatindeyiz.

Pulmoner post-travmatik psödokistlerin tanısında bilgisayarlı tomografinin yeri tartışılmaz, fakat bazı olgularda direk akciğer grafisi ile tanı konulabilir. Radyolojik olarak kontüzyon alanı içerisinde oval, yuvarlak, hava sıvı seviyesi olabilir veya tamamen hava kistleri şeklinde, değişik yapılarda ve büyüklüklerde tek veya birden fazla kaviter lezyonlar şeklinde görülebilirler. Akciğerlerin her bölgesinde görülebilmekle birlikte çoğunlukla alt zonlarda yerleşirler. Künt travma sonrasında ilk bir kaç saat içinde veya günler sonra oluşabilirler (2, 4). Ayırıcı tanıda kaviter lezyonla seyreden diğer patolojiler akılda bulundurulmalıdır. Fakat travma sonrası erken dönemde oluşması ve iyi bir anemnez tanıyı kolaylaştırır. Acil serviste özellikle travma sonrası kontüzyon içerisinde kaviter lezyonların görülmesi öncelikli olarak psödokist oluşumunu düşündürmelidir. Pulmoner post-travmatik psödokistler genellikle spesifik bir tedaviye ihtiyaç göstermezler. Fakat psödokiste bağlı komlikasyonlar geliştiği zaman cerrahi tedavi gerekebilir. Çaylak ve ark. (5) travma sonrası psödokist oluşan ve medikal tedavi ile takip ettikleri iki hastalarının 2. ve 3. aylardaki tomografi takiplerinde psödokistin progresif olarak küçüldüğünü ve her iki olgularınında cerrahi tedaviye gerek kalmadan üç ay içerisinde iyileştiğini bildirmişler. Bizim olgumuzda da iki ay içerisinde me- 

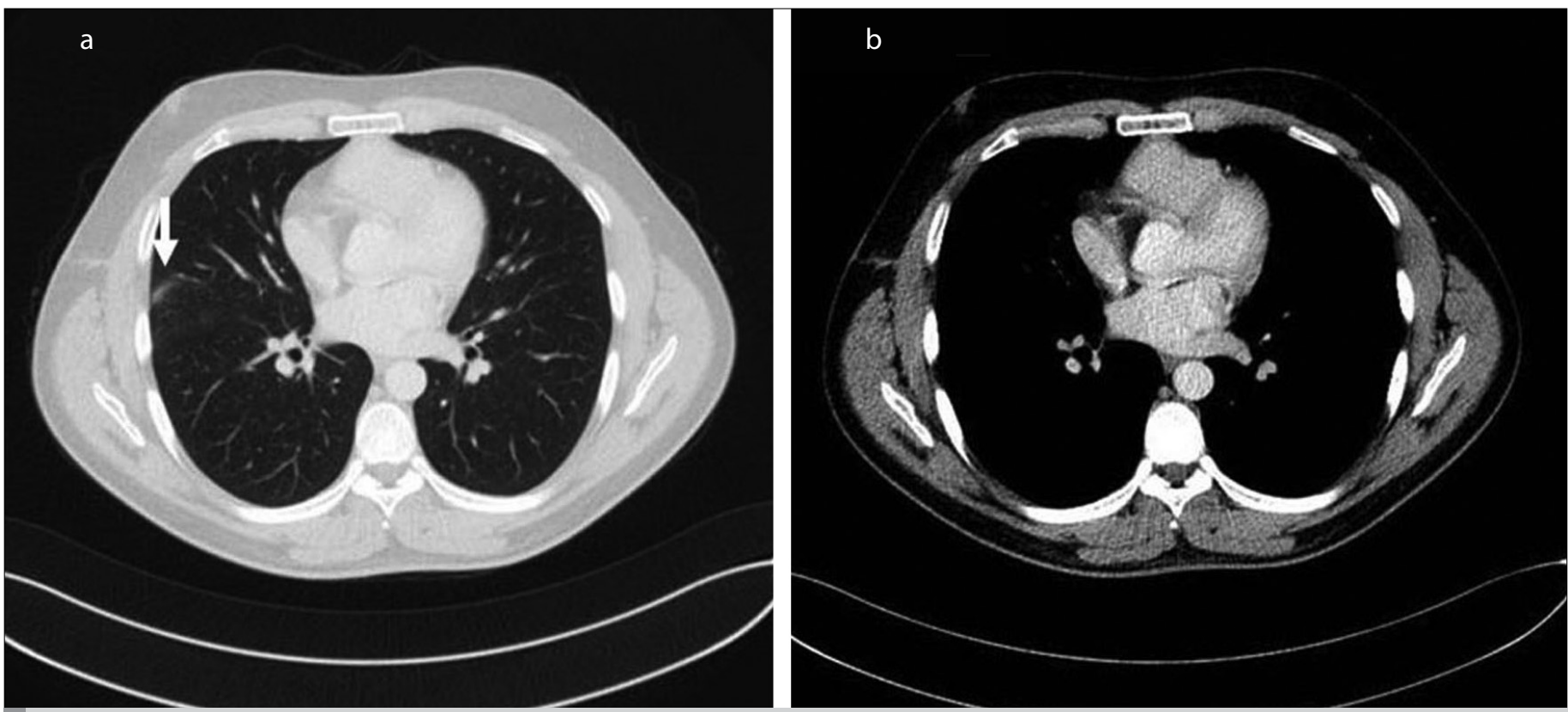

Resim 2. a, b. Travmadan yetmiş gün sonra çektirilen aksiyal bilgisayarlı tomografi'de sadece parankimal pencerede minimal bir fibrotik sekel görünümü (beyaz ok) izlenmekte

dikal tedavi ile pulmoner kontüzyonun ve psödokistlerin tamamen iyileştiği, cerrahi tedaviye gerek kalmadığı gözlendi ve tomografi takibi ile doğrulandı. Moore ve ark. (6) pulmoner psödokistlerin \% 38'inin apseleştiği ve cerrahi müdahale gerektiğini bildirmişler. Benzer şekilde Arıbaş ve ark. (7) dört psödokist hastalarının iki tanesinde bir ay içerisinde psödokistlerin büyüdüğünü ve cerrahi rezeksiyon gerektirdiğini, bu nedenle travma sonrası psödokist oluşan hastaların özellikle ilk on gün yakın takip edilmesi gerektiğini bildirmişler. Yazkan ve ark. (8) psödokist rezorbe oluncaya kadar görüntüleme yöntemleriyle yakın takip edilmesi gerektiğini, profilaktik antibiyotik tedavisinin ihtiyaç olabileceğini önermişlerdir. Biz de özellikle travma sonrası pulmoner psödokist oluşmuş hastaların ilk bir hafta yakın takip edilmesi gerektiği, bir haftanın sonunda enfeksiyon, apseleşme, progresif büyüme bulguları yoksa hastanın medikal tedavi ile özellikle ilk iki ay radyolojik olarak yakın takip etmek şartı ile taburcu edilebileceği düşüncesindeyiz.

\section{Sonuç}

Künt toraks travması sonrası nadiren gelişen post-travmatik pulmoner psödokistler genellikle klinik açıdan iyi seyir gösterirler. Psödokist saptanan olgularda komplikasyon gelişmedikçe cerrahi tedaviye gerek olmadığı ve bu tür olgularda geniş spektrumlu antibiyotik, analjezik antiinflamatuar, mukolitik ekspektoran ve bronkodilatör tedavi ile radyolojik olarak yakın takibin yeterli olacağı kanaatindeyiz.

\section{Conflict of Interest}

No conflict of interest was declared by the authors.

Peer-review: Externally peer-reviewed.

Informed Consent: Written informed consent was obtained from patients who participated in this case.

\section{Author Contributions}

Concept - I.D.; Design - I.D.; Supervision - I.D., H.E.Ç.; Funding - İ.D.; Materials - I.D., A.D.; Data Collection and/or Processing - I.D., H.E.Ç.; Analysis and/or Interpretation - I.D., A.D.; Literature Review - I.D., H.E.Ç.; Writer - I.D.; Critical Review - I.D., A.D.

Financial Disclosure: No financial disclosure was declared by the authors.

\section{Çıkar Çatışması}

Yazarlar herhangi bir çıkar çatışması bildirmemişlerdir.

\section{Hakem değerlendirmesi: Dış bağımsız.}

Hasta Onamı: Yazılı hasta onamı bu olguya katılan hastalardan alınmıştır.

\section{Yazar Katkıları}

Fikir - I.D.; Tasarım - I.D.; Denetleme - I.D., H.E.Ç.; Kaynaklar - I.D.; Malzemeler - I.D., A.D.; Veri toplanması ve/veya işlemesi - I.D., H.E.Ç.; Analiz ve/veya yorum - I.D., A.D.; Literatür taraması - I.D., H.E.Ç.; Yazıyı yazan I.D.; Eleştirel İnceleme - I.D., A.D.

Finansal Destek: Yazarlar herhangi bir finansal destek bildirmemişlerdir.

\section{Kaynaklar}

1. Chon SH, Lee CB, Kim H, Chung WS, Kim YH. Diagnosis and prognosis of traumatic pulmonary psuedocysts: a review of 12 cases. Eur J Cardiothorac Surg 2006; 29: 819-23. [CrossRef]

2. De A, Peden JC, Nolan J. Traumatic pulmonary cysts. Anaesthesia 2007; 62: 409-11. [CrossRef] 
3. Stulz P, Schmitt HE, Hasse J, Grädel E. Traumatic pulmonary pseudocysts and paramediastinal air cyst: two rare complications of blunt chest trauma. J Trauma 1984; 24: 850-3. [CrossRef]

4. Melloni G, Cremona G, Ciriaco P, Pansera M, Carretta A, Negri G, et al. Diagnosis and treatment of traumatic pulmonary pseudocysts. J Trauma 2003; 54: 737-43. [CrossRef]

5. Çaylak H, Kavaklı K, Sapmaz E, Yücel O, Genç O. Traumatic pulmonary pseudocyst: two case reports. Ulus Travma Acil Cerrahi Derg 2011; 17: 269-72. [CrossRef]
6. Moore FA, Moore EE, Haenel JB, Waring BJ, Parsons PE. Posttraumatic pulmonary pseudocyst in the adult: pathophysiology, recognition and selective management. J Trauma 1989; 29: 1380-5. [CrossRef]

7. Arıbaş OK, Emlik D, Görmüş N. Post-travmatik akciğer psödokistleri. S.Ü.Tıp Fak Derg 2001; 17: 207-12.

8. Yazkan R, Özpolat B, Şahinalp Ş. Diagnosis and management of posttraumatic pulmonary pseudocyst. Respir Care 2009; 54: 538-41. 